\title{
TORSIÓN SECUNDARIA DEL OMENTO MAYOR: UNA CAUSA POCO FRECUENTE DE DOLOR EN HERNIA INGUINAL COMPLICADA*
}

\author{
Drs. Laura Dinu ${ }^{1}$, David Ibáñez M. ${ }^{1}$, Celia Bernal L. ${ }^{1}$, Jorge González G. ${ }^{1}$ \\ 1 Servicio de Radiodiagnóstico, Hospital Universitario Miguel Servet, Zaragoza. \\ España.
}

\begin{abstract}
Secondary torsion of the greater omentum, an unusual cause of complicated inguinal hernia

Background: Secondary torsion of the greater omentum due to a complicated hernia is uncommon. Case report: We report a 43 years old male presented to the emergency room for pain in the right lower quadrant of the abdomen. An abdominal CT scan showed that mesenteric fat was herniating through the right inguinal orifice with a whirling pattern, suggesting a complicated hernia secondary to torsion of the greater omentum. The patient was operated and the preoperative diagnosis was confirmed.
\end{abstract}

Key words: Inguinal hernia, omentum, torsion.

\section{Resumen}

Introducción: La torsión del omento mayor en el interior de un orificio herniario es una entidad muy infrecuente como complicación de una hernia. Caso clínico: Presentamos el caso de un paciente varón de 43 años que acude a Urgencias por cuadro de dolor en fosa ilíaca derecha (FID). El estudio mediante tomografía computarizada muestra un patrón "en remolino" en la grasa mesentérica que se introduce en el orificio inguinal derecho, sugerente de hernia complicada secundaria a torsión de omento mayor. Los hallazgos quirúrgicos y anatomopatológicos confirman el diagnóstico. La torsión de omento mayor es una causa poco frecuente de complicación de hernia inguinal.

Palabras clave: Hernia inguinal complicada, torsión omento mayor.

\footnotetext{
*Recibido el 18 de mayo de 2013 y aceptado para publicación el 27 de junio de 2013.

Los autores no refieren conflictos de interés.

Correspondencia: Dra. Laura Dinu

Paseo Isabel La Católica 1-3, 50009, Zaragoza, España.

laura_dinu1@yahoo.com
} 


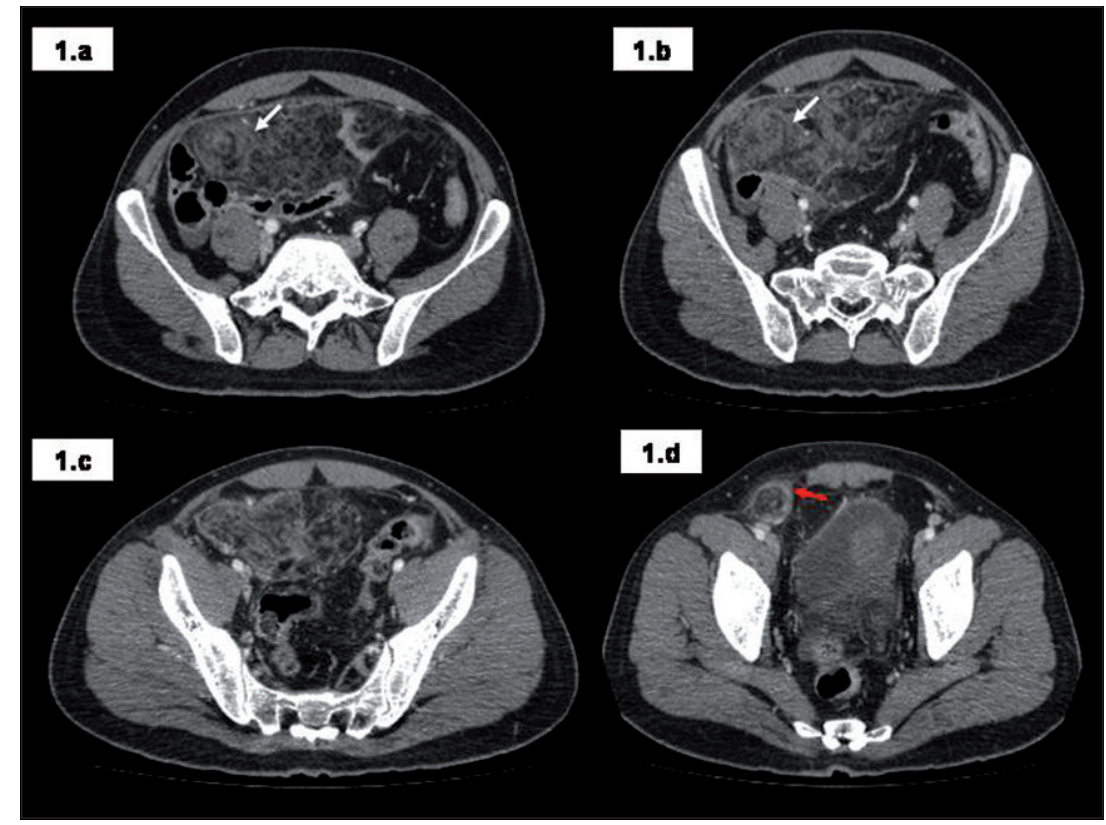

Figura 1. Estudio TC multicorte con contraste intravenoso en plano axial, con planos consecutivos (a, b, c, d) donde se identifica signo del "remolino" (flecha blanca) en FID con marcados signos inflamatorios de la grasa mesentérica. Dicho remolino se introduce en hernia inguinal (flecha roja) de contenido graso y con pared engrosada.

\section{Caso clínico}

Varón asiático de 43 años con dolor abdominal de $30 \mathrm{~h}$ de evolución, con comienzo brusco en fosa ilíaca derecha (FID), que posteriormente se generaliza al resto del abdomen. Como síntoma asociado refiere disuria desde hace $24 \mathrm{~h}$ por lo cual inicia tratamiento antibiótico extrahospitalario. Como antecedentes patológicos de interés cabe reseñar la existencia de una hernia inguinal derecha. A la exploración física en el Servicio de Urgencias presenta abdomen distendido, doloroso a la palpación en todo el hemiabdomen inferior, con defensa y signos de irritación peritoneal en FID. El peristaltismo está conservado. La analítica demuestra una discreta leucocitosis $(11.800 / \mu \mathrm{l})$ con neutrofilia $(8.300 \mu 1)$ y escasa flora bacteriana en orina.

Se solicita estudio ecográfico en el que se detecta presencia de líquido libre en FID con afectación inflamatoria de la grasa mesentérica regional. Ante estos hallazgos se completa el estudio con tomografía computarizada (TC) que muestra importante afectación inflamatoria de la grasa mesentérica en pelvis menor y "signo del remolino" en FID con extensión hacia el canal inguinal derecho. A ese nivel se visualiza hernia de contenido graso, sin asas intestinales en su interior (Figuras 1 y 2). Como variante de la normalidad, se asocia la presencia de al menos 3 ramas de la vena mesentérica superior de localización atípica, una de ellas rodeando posteriormente a la arteria del mismo nombre.
El paciente es intervenido de forma urgente iniciándose el acto quirúrgico por vía laparoscópica que, tras identificar plastrón de epiplón mayor isquémico, se amplía a vía abierta por laparotomía media, realizándose omentectomía del epiplón mayor isquémico herniado, y posteriormente hernioplastía inguinal.

El estudio anatomopatológico confirma la presencia de lesiones histológicas concordantes con isquemia vascular en epiplón mayor.

\section{Discusión}

La torsión primaria del epiplón es una condición clínica poco frecuente y se debe considerar dentro de las causas de abdomen agudo. Su principal manifestación es el dolor abdominal, que puede simular otras patologías quirúrgicas intraabdominales, como apendicitis, diverticulitis, colecistitis e incluso patologías de origen ginecológico El diagnóstico generalmente se realiza durante la laparotomía siendo la resección quirúrgica el manejo definitivo de dicha entidad.

Fue descrita por primera vez por Eitel en 1899, y desde entonces se han descrito en la literatura menos de $300 \operatorname{casos}^{1}$. Esta entidad generalmente se presenta en pacientes adultos entre la cuarta y quinta décadas de vida, siendo el género masculino afectado más frecuentemente ${ }^{2}$. La torsión del omento mayor se clasifica en primaria o secundaria según su etiología. Para la torsión primaria (idiopática) se han descrito 


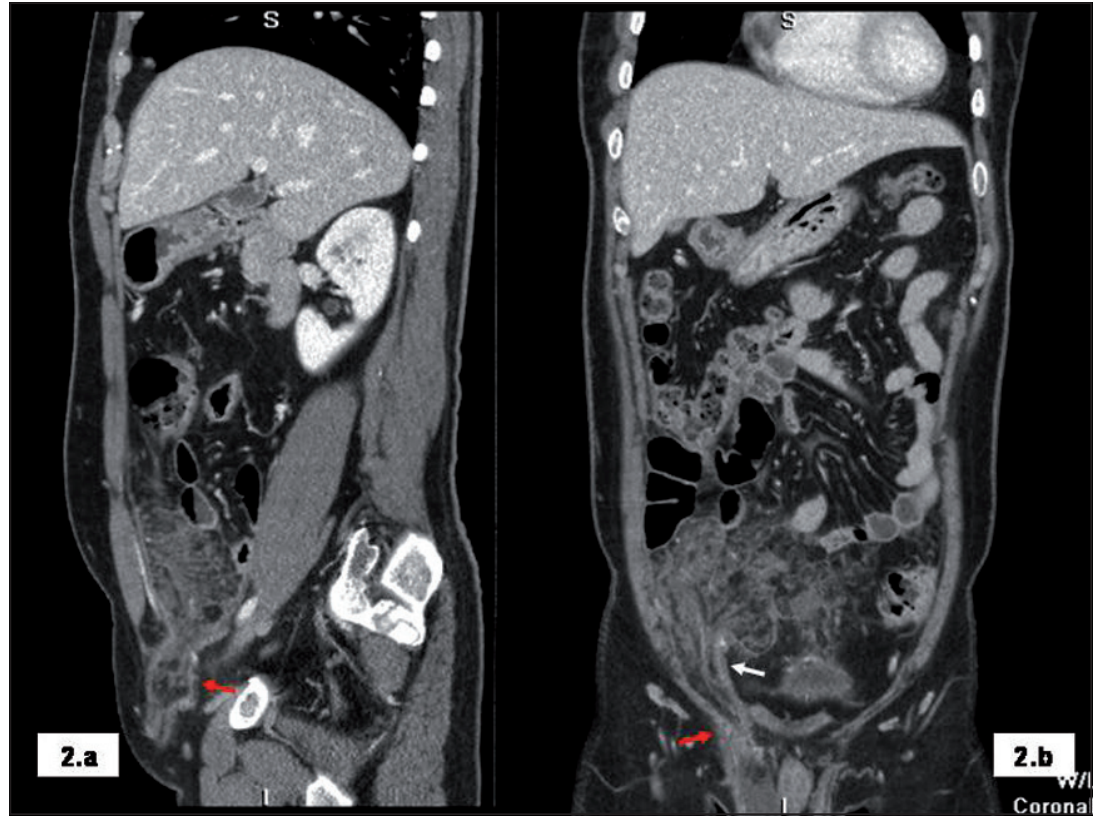

Figura 2. Estudio TC multicorte con contraste intravenoso en plano sagital (a) y coronal (b). Se visualiza la afectación inflamatoria introduciéndose en canal inguinal (flecha roja) dirigiéndose los vasos torsionados (flecha blanca) hacia la hernia.

algunos factores predisponentes como omento bífido o presencia de venas omentales redundantes. La torsión secundaria suele estar asociada a patologías abdominales: hernias, tumores o adherencias ${ }^{3}$.

Dado que la mayoría de los casos descritos afectan el lado derecho, es muy importante tenerla en cuenta como diagnóstico diferencial del dolor abdominal en dicho lado, ya que puede simular colecistitis, apendicitis aguda, o incluso apendagitis ${ }^{4}$.

Ante la presencia de una hernia inguinal complicada, la principal sospecha clínica es habitualmente la incarceración de asas, siendo la lesión del epiplón una etiología excepcional de la misma.

En el proceso diagnóstico, la TC es una herramienta fundamental para la detección de esta entidad. En dicho estudio se visualiza una imagen característica de masa abdominal de densidad grasa que presenta en su interior estriaciones hiperdensas, adoptando una distribución en espiral, en relación con el pedículo vascular torsionado ${ }^{3,5}$. La distribución concéntrica del pedículo vascular es un signo clave del diagnóstico. Su ausencia nos obliga a plantear diagnóstico diferencial con otras entidades que se presentan en la TC como masa omental de densidad grasa: lipoma, liposarcoma, angiomiolipoma, apendagitis epiploica y paniculitis mesentérica ${ }^{5-7}$.

\section{Conclusión}

Se trata de una entidad poco frecuente de difícil diagnóstico, pero que debe ser tenida en cuenta por el cirujano ante un abdomen agudo, siendo la técnica de elección para su diagnóstico preoperatorio el TC, y el manejo de elección la resección quirúrgica.

\section{Referencias}

1. Uscategui $\mathrm{CH}$. Torsión primaria de epiplón: Caso clínico. Rev Chil Cir. 2010;62:408-11.

2. Thum-Umnuaysuk S. Primary Torsion of the Greater Omentum: Report of a Case. J Med Assoc Thai 2009;92:691-3.

3. Steinauer-Gebauer AM, Yee J, Lütolf ME. Torsion of the Greater Omentum with Infarction: The Vascular Pedicle Sign. Clinical Radiology 2001;56:999-1002.

4. Aoun N, Haddad-Zebouni S, Slaba S, Noun R, Ghossain M. Leftsided omental torsion: CT appearance. Eur Radiol. 2001;11:96-8.

5. Hernández RH, Fernández JM, Lozano $\mathrm{O}$, Pérez J, Hernández P, Gutiérrez A y cols. Torsión completa del epiplón mayor como causa de abdomen agudo. Contribución de la TC en el diagnóstico preoperatorio. Cir Esp. 2002;72:362-4.

6. Naffaa LN, Shabb NS, Haddad MC. CT findings of omental torsion and infarction Case report and review of the literature. Journal of Clinical Imaging 2003;27:1168.

7. Ergun T, Lakadamyali H, Karabulut Z, Dogan T. Omental torsión without a whirl sign. Australas Radiol. 2007;51:158-60. 